\title{
Undergraduate Ophthalmology Teaching in Saudi Arabia: Assessment, Analysis, and Comparisons
}

\author{
Ruba M Alselaimy' \\ Hani B ALBalawi ${ }^{2}$ \\ 'Department of Ophthalmology, College \\ of Medicine, King Saud University, Saudi \\ Arabia; ${ }^{2}$ Ophthalmology Division, \\ Department Of Surgery, Faculty Of \\ Medicine, University Of Tabuk, Tabuk, \\ Saudi Arabia
}

Background: The International Council of Ophthalmology (ICO) considers ophthalmology a core curriculum subject for medical students. To date, there is no unified guideline assessing the efficacy of ophthalmology curricula in Saudi medical schools. Hence, we aimed to investigate the adequacy of undergraduate ophthalmology education in Saudi Arabia compared with the ICO guidelines.

Methods: In this cross-sectional study, an online questionnaire was distributed randomly to medical graduates in different Saudi medical schools. We reached 31 medical schools (public and private) in different regions of Saudi Arabia.

Results: From medical schools across Saudi Arabia, 317 participants were enrolled in the study. Our study outcomes followed the ICO guidelines in multiple areas, including having ophthalmology training during medical school (93.4\%), ophthalmology course duration of 2 weeks $(56.2 \%)$, necessary knowledge for patients' referral $(55.8 \%)$, competency in most basic ophthalmic skills, and participants receiving different teaching methods (theoretical lectures and clinical settings). In addition, $58.7 \%$ of the participants considered ophthalmology education a significant factor in choosing a future residency program.

Conclusion: In our study, most Saudi medical schools followed the ICO guidelines, as numerous graduates are competent in many basic ophthalmic skills. A structured national guideline must be established to ensure that future general practitioners can deal with ophthalmic patients and to establish a Saudi gold-standard eyesight health program.

Keywords: ophthalmology, education, medical school, undergraduate, curriculum, Saudi

\section{Introduction}

Over years and decades, undergraduate ophthalmology content, ophthalmology placement within the medical curriculum, and teaching methods have been controversial issues among medical education experts. Moreover, with expanding medical knowledge and limited time within medical school curricula, the ophthalmology rotation in medical schools has declined, and some graduated doctors have noticed feeling discomfort when dealing with ophthalmological complaints. ${ }^{1-4}$ Despite this, the literature reveals that $3-19 \%$ of primary care consultations are ophthalmic in nature. ${ }^{5}$ Furthermore, the prevalence of eye diseases is expected to increase with the growing population. ${ }^{6}$ Having the basics of ophthalmology is essential for general practitioners, emergency physicians, and junior doctors to treat and refer ophthalmic patients. ${ }^{7}$ Moreover, an accurate level of referral is critical to prevent poor patient outcomes; thus, it is necessary to increase ophthalmic education for all medical graduates. ${ }^{8}$ For that reason, the curricula of most modern medical schools consider ophthalmology as a core subject for medical
Correspondence: Hani B ALBalawi

Email hb.albalawi@ut.edu.sa 
students rather than an elective course. ${ }^{9}$ Therefore, understanding the nature of the current curricula is vital to expand the extent of knowledge and skills gained during ophthalmic rotation in medical schools.

Establishing fundamental knowledge and skills in ophthalmology is crucial for medical students to choose their future careers. Pursuing a specific medical career seems to be influenced by the manners of teaching and duration of exposure to medical subjects..$^{10}$ In Saudi studies, ophthalmology was selected as one of the top preferred specialties by undergraduate medical students, with $5.6 \%$ choosing ophthalmology as their first career choice. ${ }^{11,12}$

To achieve ophthalmic educational goals, the International Council of Ophthalmology (ICO) recommends implementing specific teaching methods incorporating lectures, clinical demonstrations, illustrative case method study, and evidence-based medicine teaching (where ophthalmic education is paired with neuroscience, neurology, endocrinology, and geriatric medicine). ${ }^{9}$ In addition, a competency-based ophthalmology curriculum seems to enhance the overall ophthalmology knowledge of medical graduates, resulting in a significant increase in academic performance and student satisfaction. ${ }^{13}$

In the past decade, the number of Saudi medical schools has increased dramatically, from five to 21 , and further expansion is anticipated. ${ }^{14}$ Curricula of varying quality and different teaching methods are expected to exist with this expansion. However, there are no systematic guidelines to assess the efficacy of ophthalmology curricula in Saudi medical schools. Hence, we aimed to investigate the self-reported adequacy of undergraduate education in Saudi Arabia compared with the ICO guidelines.

\section{Methods}

This is a cross-sectional study, in which an online questionnaire was distributed randomly to medical graduates who have completed their medical school curricula and are currently in their 12-month internship year. We deemed these participants to have sufficient experience in medical education programs to provide valuable responses. The questionnaire was distributed electronically to various Saudi medical schools via emails and social media platforms (eg, Twitter, Telegram, and WhatsApp). Representatives of each medical school were allocated and contacted to receive the total number of the corresponding batch, and questionnaires were distributed through each batch's representative. We reached 31 medical schools (public and private) from different regions of Saudi Arabia. The questionnaire (Appendix 1) consisted of 35 questions, including demographic data (age, gender, and medical college), data about participants' knowledge of ophthalmology curricula, and basic skills of ophthalmology known, taught, or experienced via any means for the participants. Questions were developed based on the ICO guidelines and previously published research with similar aims. ${ }^{9,15}$

Informed consent was obtained from the participants electronically, after the aims of the study and planned use of the data and their responses had been explained, before beginning the questionnaire.

Data were characterized by demography. Data were analyzed using IBM SPSS statistics software for Windows, version +21.0 (IBM Corp, Armonk, NY, USA). A $P$-value $\leq 0.05$ and $95 \%$ confidence intervals (CIs) were used to report statistical significance and precision of results, and associations between study variables were assessed using the chi-squared test, $t$-test, and odds ratios.

\section{Results \\ Demographics}

A total of 317 participants out of 4409 graduates from 31 medical schools across Saudi Arabia were enrolled in the study. Of the subjects, 162 (51.1\%) were female, and 155 (48.9\%) were male; the mean age was 24.35 years. A high proportion of respondents $(83.6 \%)$ were public medical school graduates, with the remaining $16.4 \%$ from private medical schools.

The highest response rates came from Jazan University in Jazan city, King Khalid University in Abha city, and King Saud University in Riyadh city, at $11.4 \%, 10.1 \%$, and $8.2 \%$, respectively. The distribution of respondents across medical colleges of the Kingdom of Saudi Arabia is shown in Figure 1.

\section{Ophthalmology Curricula}

The vast majority (93.4\%) of the subjects had received a mandatory ophthalmology component on the curriculum (Figure 2). Of the total 317 respondents, $60.3 \%$ received their ophthalmology training during the fourth year, $29 \%$ in the final year, $7.6 \%$ in the third year, and 3.2\% had not experienced an ophthalmology rotation (Figure 3). The course length ranged from 5 days to 3 weeks or more; most of the responses (56.2\%) completed a rotation lasting for 2 weeks (Figure 4). Ophthalmology exposure was classified into five categories 
Saudi medical schools

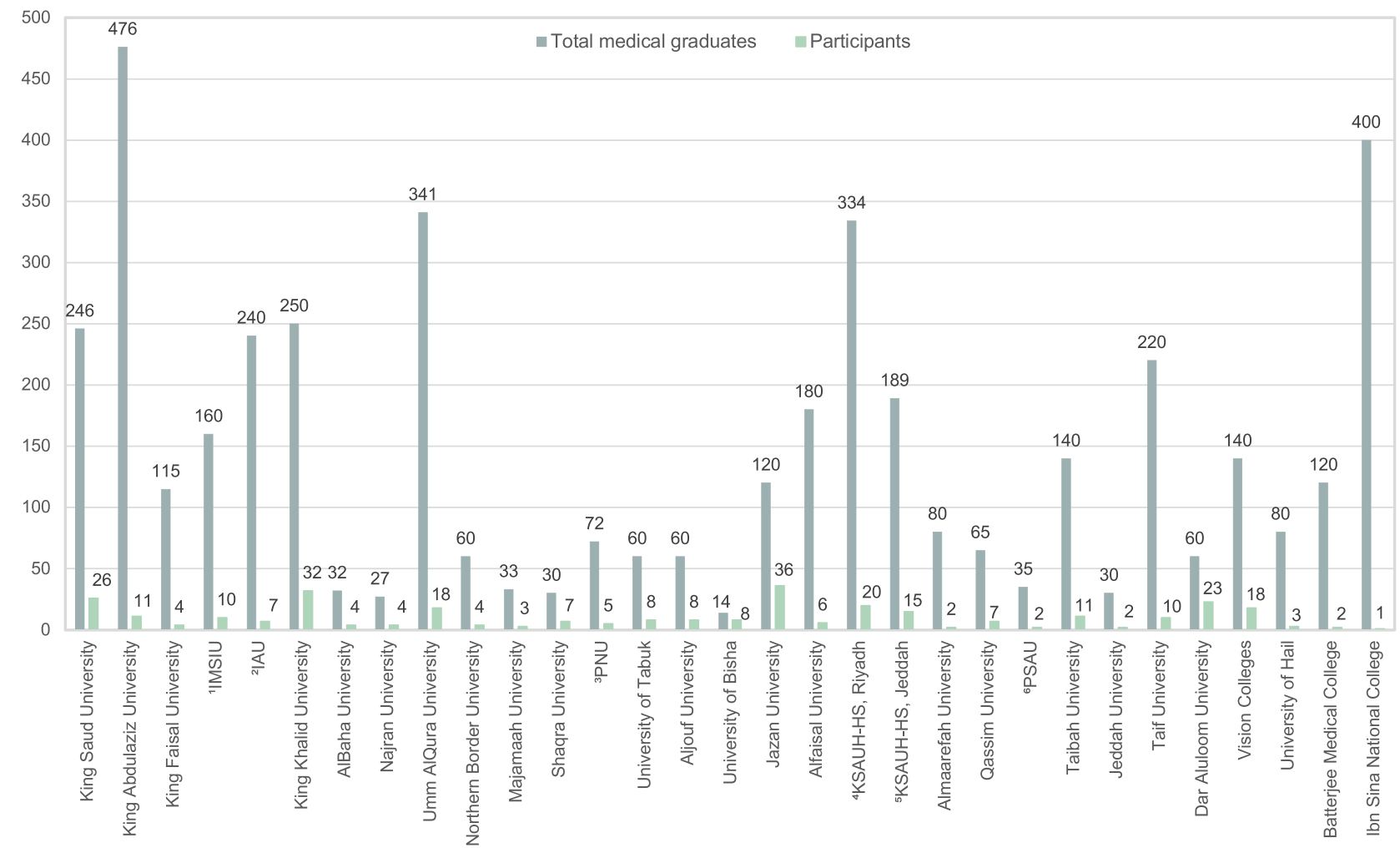

'IMSIU, Imam Muhammed Ibn Saud Islamic University ${ }^{2} \mathrm{IAU}$, Imam Abdulrahman Bin Faisal University

${ }^{3} \mathrm{PNU}$, Princess Nourah Bint Abdulrahman University
${ }^{4} \mathrm{KSAUH}-\mathrm{HS}$ - Riyadh, King Saud Bin Abdulaziz University For Health Sciences, Riyadh ${ }^{5}$ KSAUH-HS - Jeddah, King Saud Bin Abdulaziz University For Health Sciences, Jeddah ${ }^{6} \mathrm{PSAU}$, Prince Sattam Bin Abdulaziz University

Figure I Number of participants from each Saudi medical school enrolled in the study.

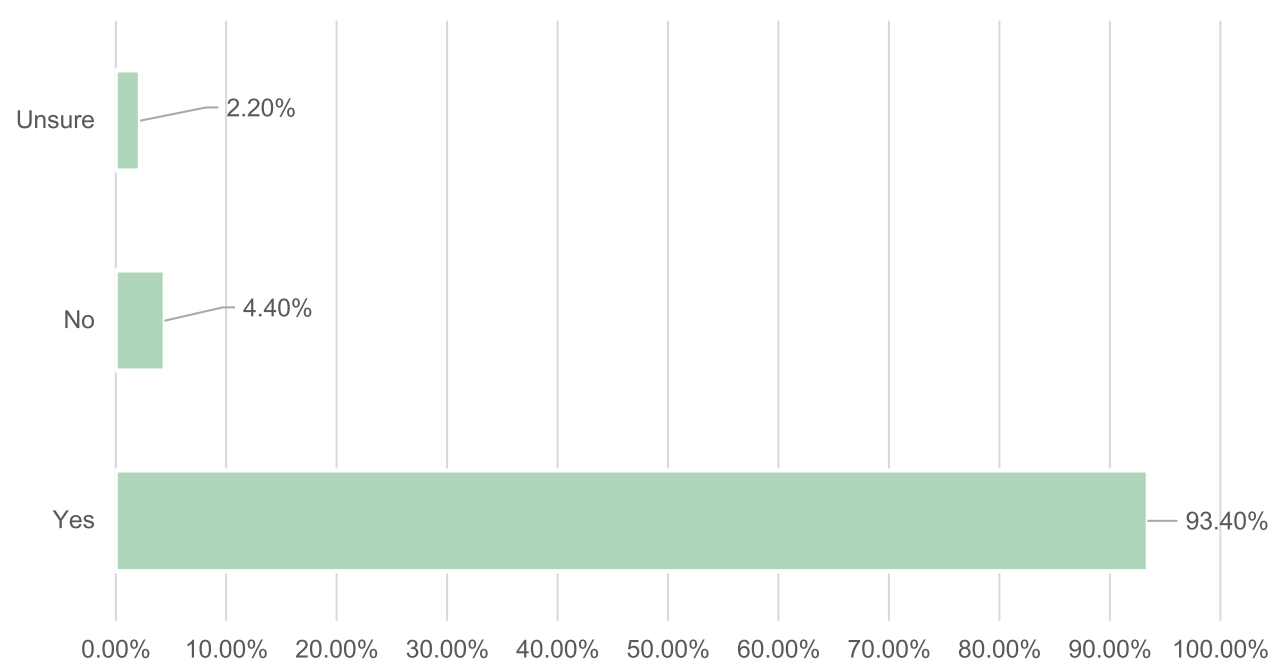

Figure 2 Mandatory ophthalmology teaching during medical school.

(no exposure, too little exposure, just the right amount, too much exposure, and unsure). Of the total participants, 163 (51.4\%) reported too little exposure, and just the right amount of exposure was reported by $126(39.7 \%)$ of respondents
(Table 1). The quality rating of the curriculum was divided into six groups (excellent, very good, average, poor, very poor, and did not receive any training). The average quality rating was the highest percentage among those groups, at $36.9 \%$ 


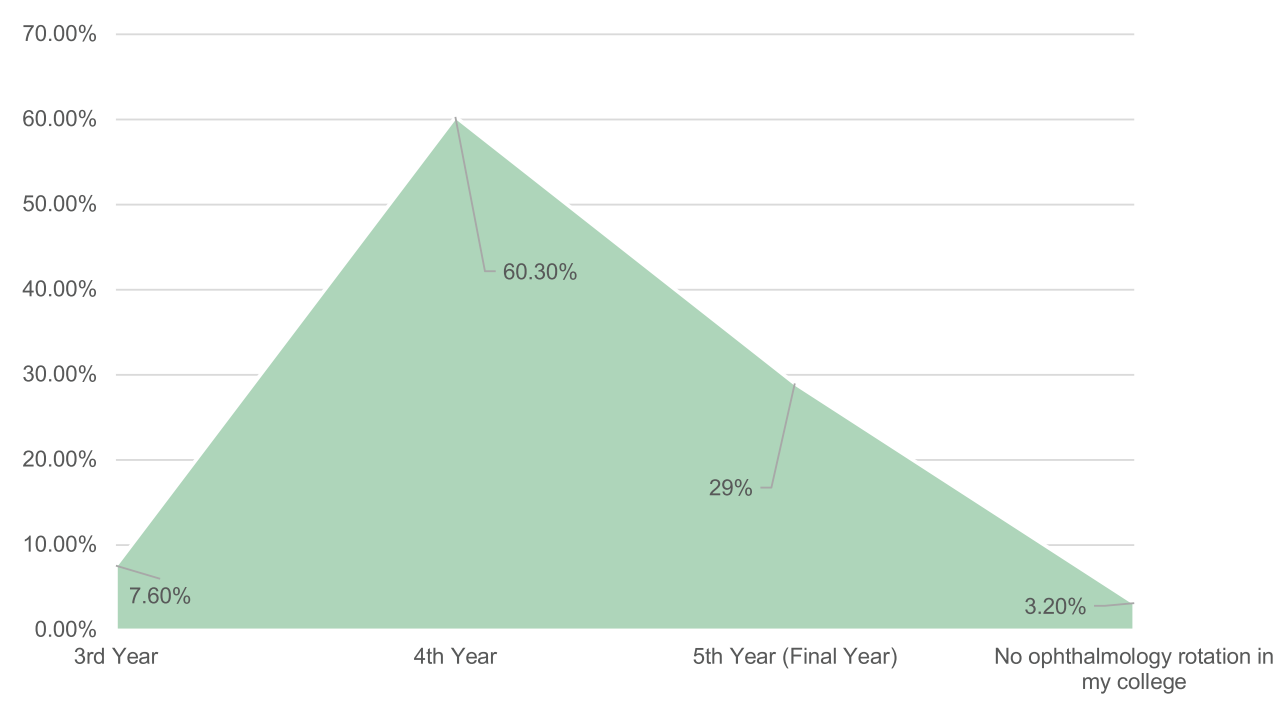

Figure 3 Timing of ophthalmology rotation during medical school.

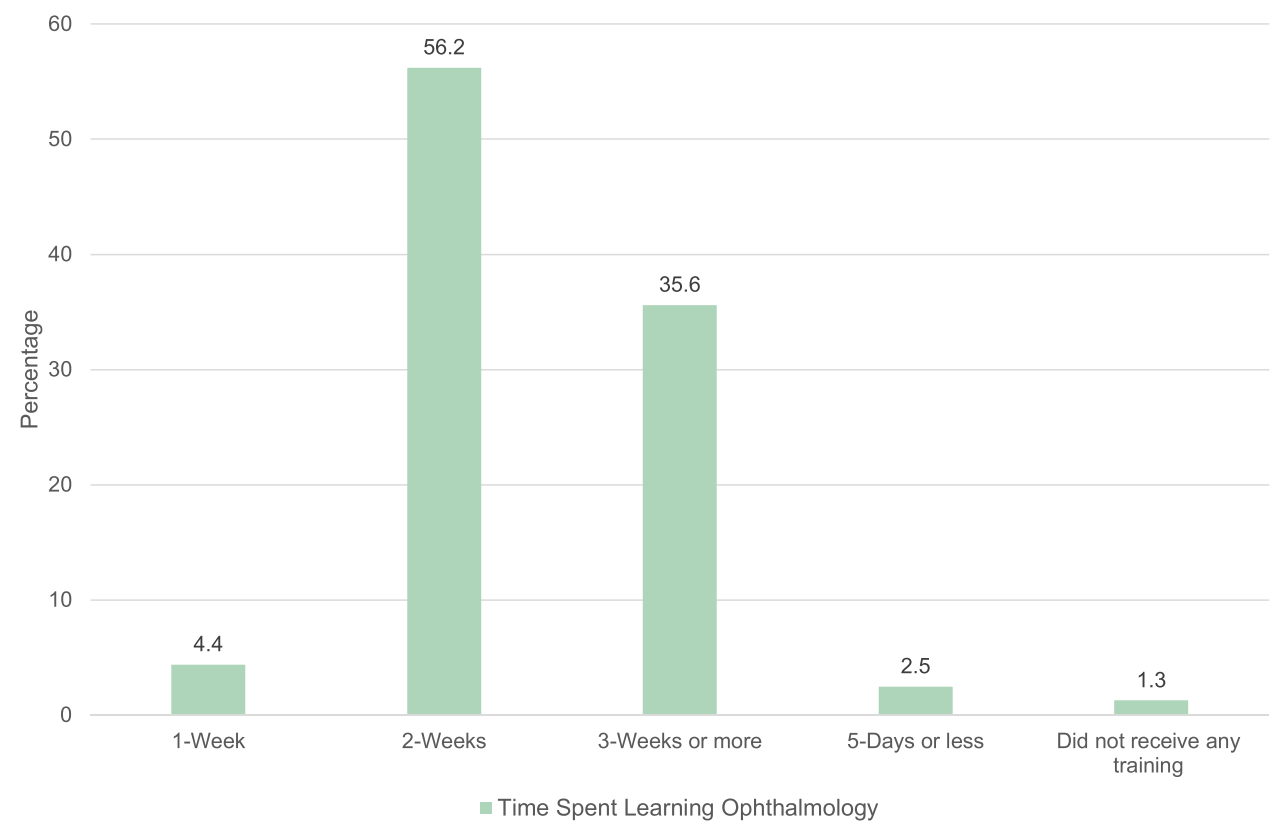

Figure 4 Time spent learning ophthalmology in medical school.

(Figure 5). The most common teaching methods, from the highest percentage to the lowest, were as follows: theoretical lectures, clinical (clinics, operation room, emergency department), small group discussions, and self-directed learning (Table 1). Of all respondents, $49.2 \%$ had observed or taken ophthalmic histories and examinations.

Ophthalmology clinics were the most common location for respondents to encounter ophthalmic patients $(66.2 \%)$, followed by $27.1 \%$ of the participants who had not encountered ophthalmic patients during training in medical school (Table 1).
When asked about subspecialty coverage during their studies, cornea and external diseases, lens and cataract, and glaucoma were given the highest exposure. On the other hand, intraocular tumors, refractive surgery, and vitreoretinal diseases were given the least exposure during medical school (Figure 6).

\section{Basic Skills of Ophthalmology}

We assessed the competencies of basic eye skills, including obtaining the ocular history, measuring visual acuity, visual field examination, extraocular motility examination, 
Table I Ophthalmology Curricula in Saudi Medical Schools

\begin{tabular}{|c|c|}
\hline Ophthalmology Curricula & $\begin{array}{c}\text { Participants, No. } \\
\text { (\%) }\end{array}$ \\
\hline \multicolumn{2}{|l|}{ Ophthalmology course exposure } \\
\hline No exposure & $13(4.1 \%)$ \\
\hline Too little exposure & $163(51.42 \%)$ \\
\hline Right amount of exposure & $126(39.75 \%)$ \\
\hline Too much exposure & $9(2.83 \%)$ \\
\hline Unsure & $6(1.9 \%)$ \\
\hline \multicolumn{2}{|c|}{ Most common location encountering ophthalmic patients } \\
\hline Ophthalmology clinic & $210(66.2 \%)$ \\
\hline Emergency department & $6(1.9 \%)$ \\
\hline Operation room & $5(1.6 \%)$ \\
\hline Family medicine practice & $8(2.5 \%)$ \\
\hline No contact with ophthalmic patients & $88(27.8 \%)$ \\
\hline \multicolumn{2}{|l|}{ Teaching methods } \\
\hline Theoretical lectures & $288(44 \%)$ \\
\hline Clinical (emergency department, operation room, clinics) & 167 (26\%) \\
\hline Small group discussion & $103(16 \%)$ \\
\hline Self-directed learning & $94(14 \%)$ \\
\hline
\end{tabular}

assessing pupillary light reflexes, pupil dilation, using a direct ophthalmoscope for fundus examination, slitlamp examination, corneal examination with fluorescein stain, intraocular pressure measurement, anterior chamber depth assessment, and patient referral (Figure 7).

A total of $58.7 \%$ of participants considered ophthalmology education an important factor in choosing their future residency program. Being trained in ophthalmology during medical school was revealed to have a significant association with planning for future residency $(P=0.005)$.

\section{Discussion}

In this study, the ICO's undergraduate curriculum guidelines were used to evaluate and compare current teaching curricula at Saudi medical schools.

Of the total participants, $93.4 \%$ had received a mandatory rather than an elective ophthalmology course, suggesting that ophthalmology is offered as a core component of the curriculum in most Saudi medical colleges. Having a mandatory ophthalmology course follows the recommendations in the ICO guidelines. This compares favorably with Canadian, British, Australasian, and Asian universities, but less so with American medical schools. ${ }^{5,15-17}$

In our study, $6.6 \%$ of the subjects said "No" or "Unsure" about the presence of mandatory teaching. This reflects that these graduates may have forgotten their ophthalmology education, either because of the superficiality of the course or because training was given over a very short period or was not provided at all.

The task force estimated the sufficient exposure time to ophthalmology to be 5-8 days (or 40-60 hours) throughout medical school. Of the respondents, $56.2 \%$ received a course lasting approximately 2 weeks (5 days/week). The length of course identified was in line with recommendations and longer than in Canadian medical schools. ${ }^{15}$

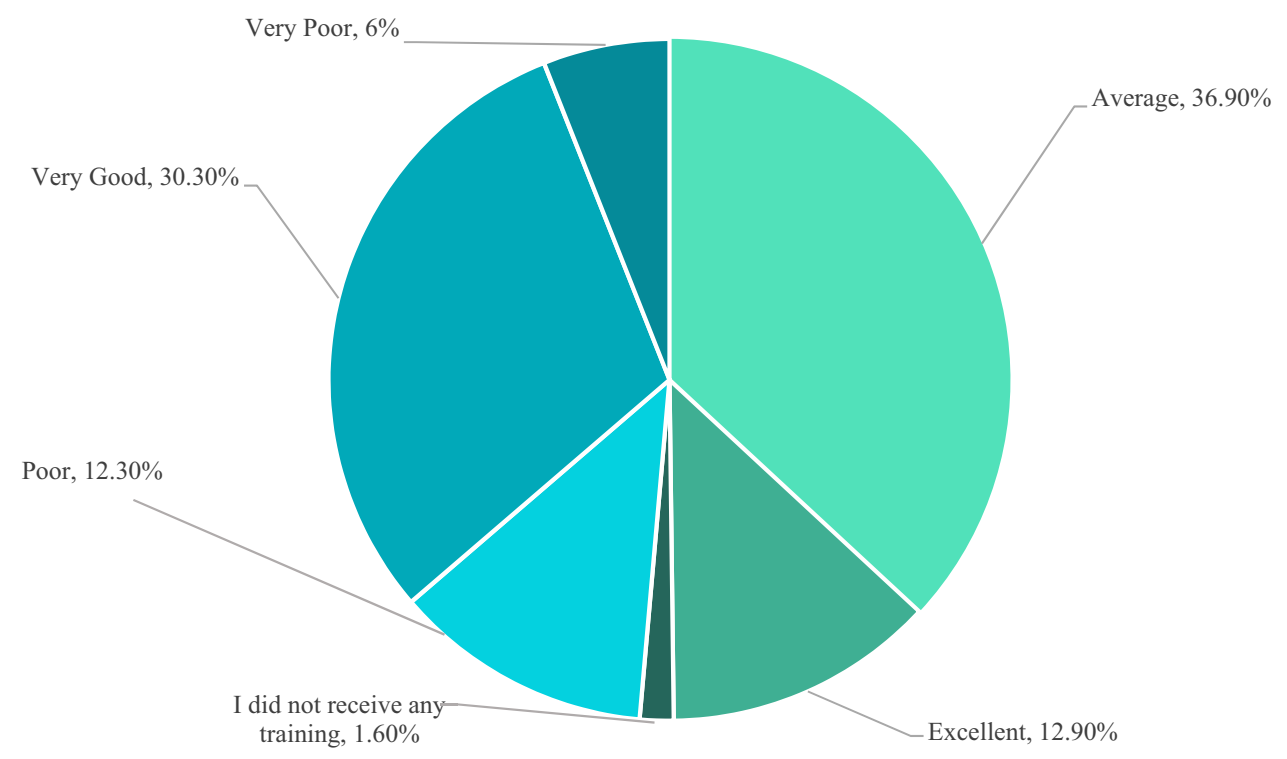

Figure 5 Quality rating of ophthalmology education in medical school. 


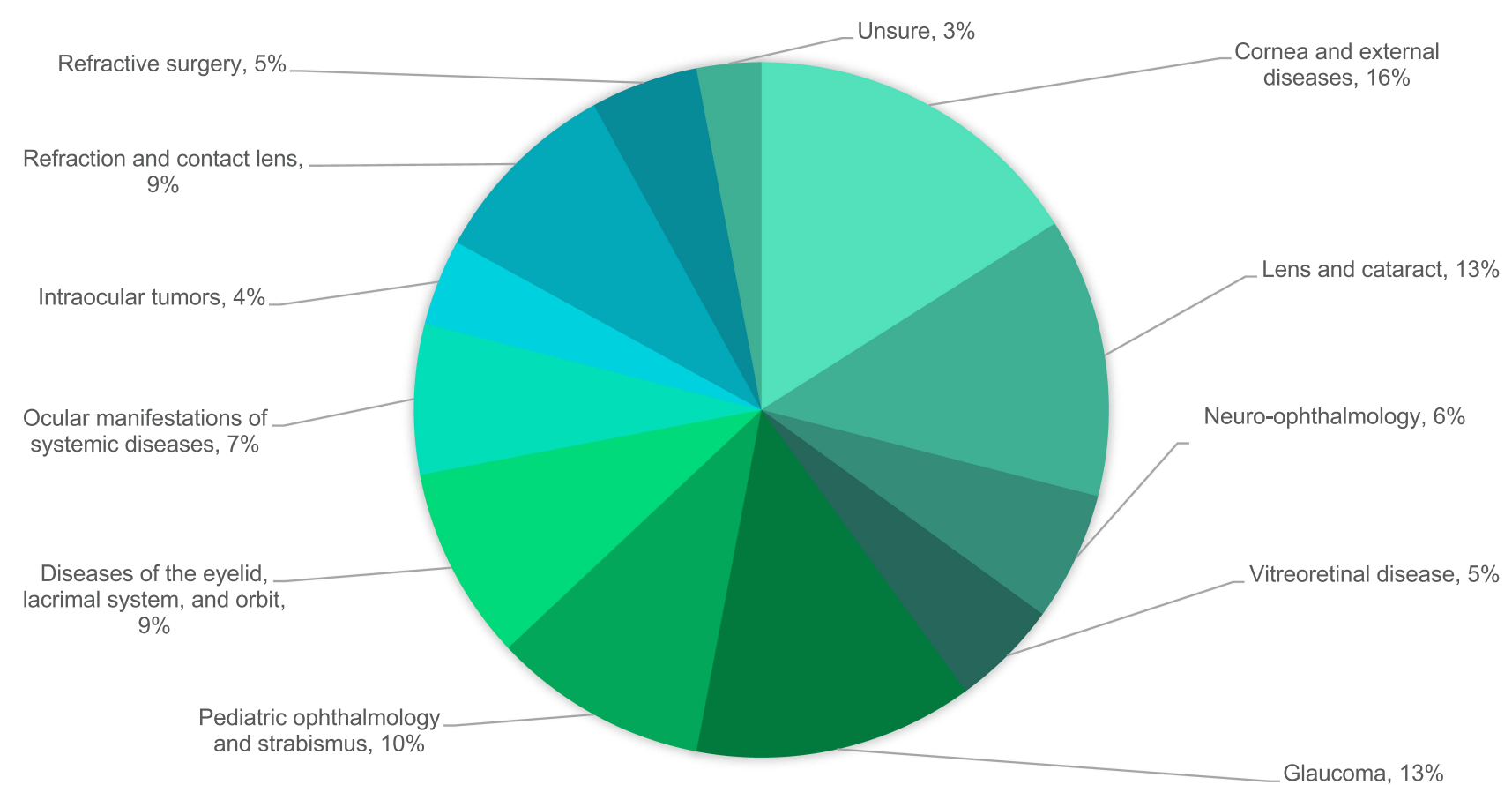

Figure 6 Exposure to ophthalmology subspecialties during medical school.

\title{
Ophthalmic skills
}

\author{
- Competent $\square$ Incompetent
}

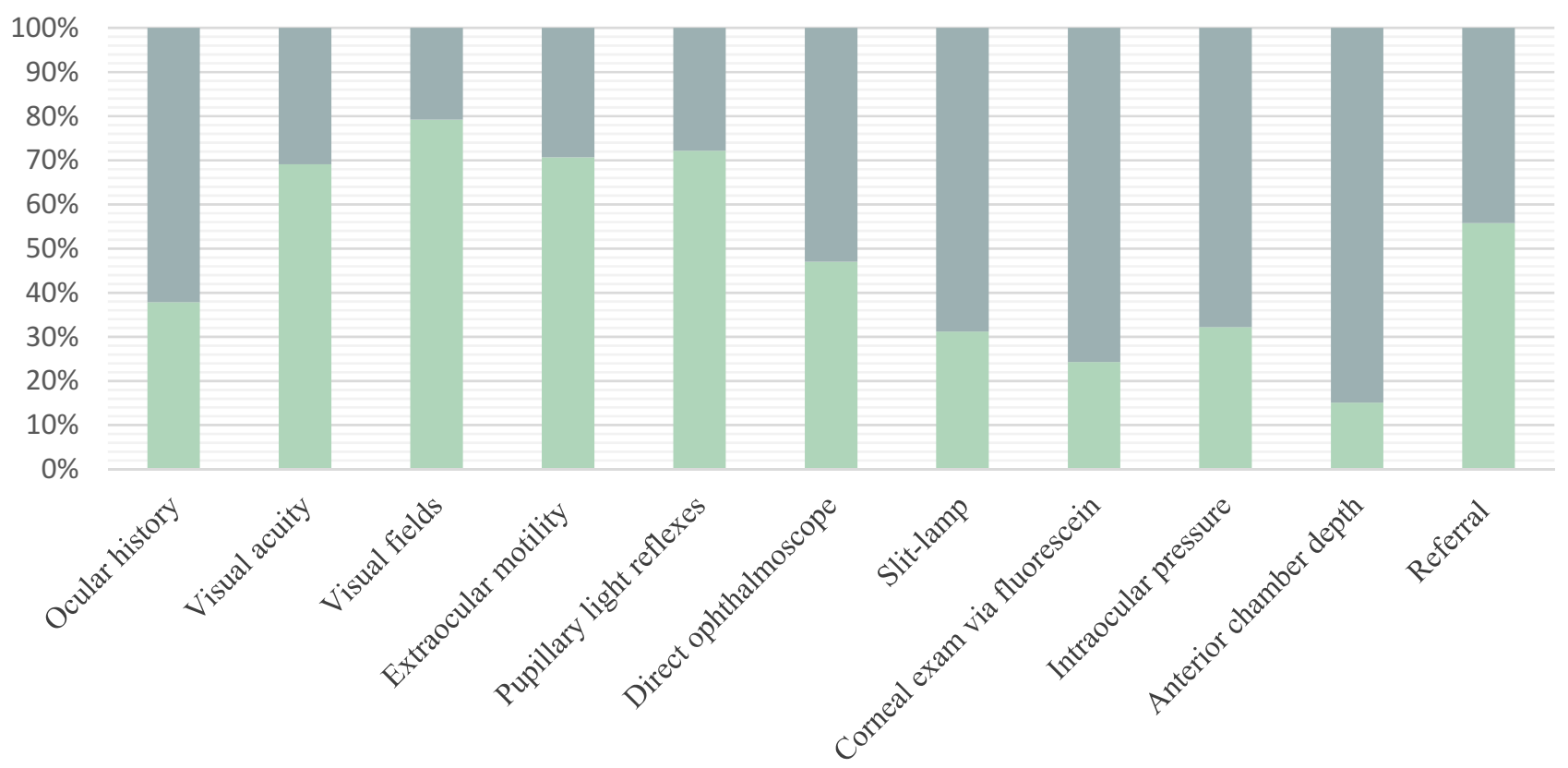

Figure 7 Competency of Saudi medical graduates in basic ophthalmic skills.

One goal suggested by the task force was diversity in teaching methods over a week. The most common teaching methods reported were theoretical lectures and clinical settings (emergency department, operation room, and clinics), representing $44 \%$ and $26 \%$, respectively. We assessed two further tutoring methods: small group 
discussions (16\%) and self-directed learning (14\%). A study at AlBaha University concluded that self-directed learning in ophthalmology is less valuable than problembased learning in the promotion of self-readiness.$^{18}$ Thus, we recommend focusing on and implementing small group discussions in the ophthalmology curriculum.

Fewer than $2 \%$ of respondents encountered ophthalmic patients in the emergency department, indicating low exposure to ophthalmic emergencies and in opposition to the objectives of medical rotations. Exposure to different ophthalmology subspecialties showed a wide variation, as demonstrated in Figure 6. This significant variation indicates a lack of standardized teaching guidelines and the low quality of the curricula.

Some medical graduates lacked competency in ophthalmic care, echoing the primary finding of a previous global ophthalmology survey. ${ }^{6}$ To improve general medical care, competency-based ophthalmology teaching is superior to traditional teaching methods. ${ }^{13,19}$ In addition, e-learning through virtual ophthalmology clinics has increased in recent years. ${ }^{19}$ Research has shown that e-learning enhances students' clinical reasoning skills in a safe environment and reduces patient stress during eye examinations. ${ }^{19}$

According to the ICO guidelines, family physicians should recognize ophthalmic diseases requiring referral. ${ }^{9}$ Our study found that $55.8 \%$ of the participants were knowledgeable regarding patient referral. Ophthalmology symptoms may be the first presenting of systemic disease, as in COVID-19, the pandemic that has changed all aspects of life, including ophthalmology teaching. Ophthalmic educators all over the world have responded to this crisis with innovative, flexible, and timely action. ${ }^{20}$

This study had some limitations. First, we assessed only eye skills and not specific knowledge gained from ophthalmology curricula. The ICO recommendations regarding the knowledge composition of an ideal ophthalmology module should be evaluated. Second, some clinical ophthalmic skills mentioned by the ICO were overlooked: measurement and interpretation of pupillary size, penlight examination of the anterior segment including upper lid eversion, ability to remove superficial corneal or conjunctival foreign bodies, and testing the red reflex. In addition, while the response rate was good, some schools had low representation (Figure 1).

We recommend an initiative step to standardize a Saudi guideline for the undergraduate ophthalmology curriculum, to be followed by all universities/colleges across the
Kingdom, to improve the outcomes of each medical graduate. In its favor, our study is the first of its kind in Saudi Arabia to assess ophthalmology courses compared to the ICO guidelines.

\section{Conclusion}

As patients' quality of life is massively affected by ophthalmic diseases, medical colleges should develop a fundamental ophthalmology curriculum in adherence with ICO guidelines to ensure higher educational benefits and an overall improvement in the excellence of health care systems.

Our study found that most Saudi medical schools follow the ICO guidelines, as most graduates are competent in many basic ophthalmic skills. However, our study identified some gaps in knowledge and some basic skills. Thus, a structured national guideline must be established to ensure that future general practitioners can deal with ophthalmic patients and to establish a Saudi goldstandard eyesight health program.

\section{Disclosure}

The authors report no conflicts of interest in this work.

\section{References}

1. GMC, General Medical Council. Tomorrow's Doctors: outcomes and standards for undergraduate medical education; 2009:1-108.

2. Byers WG. The place of ophthalmology in the undergraduate medical curriculum. Br Med J. 1922;2(3209):4-6. doi:10.1136/bmj.2.3209.4

3. Crombie AL. Ophthalmology in the undergraduate curriculum. Trans Ophthalmol Soc U K. 1976;96(1):33-34.

4. Albert DM, Bartley GB. A proposal to improve ophthalmic education in medical schools. Ophthalmology. 2014;121(6):1157-1159. doi:10.1016/j.ophtha.2014.04.003

5. Fan JC, Sherwin T, McGhee CNJ. Teaching of ophthalmology in undergraduate curricula: a survey of Australasian and Asian medical schools. Clin Exp Ophthalmol. 2007;35(4):310-317. doi:10.1111/ j.1442-9071.2006.01414.x

6. Succar T, Grigg J, Beaver HA, Lee AG. Advancing ophthalmology medical student education: International insights and strategies for enhanced teaching. Surv Ophthalmol. 2020;65(2):263-271. doi:10.1016/j.survophthal.2019.08.006

7. Hill S, Dennick R, Amoaku W. Present and future of the undergraduate ophthalmology curriculum: a survey of UK medical schools. Int J Med Educ. 2017;8:389-395. doi:10.5116/ijme.59ac.f69b

8. Nari J, Allen LH, Bursztyn LL. Accuracy of referral diagnosis to an emergency eye clinic. Can J Ophthalmol. 2017;52(3):283-286. doi:10.1016/j.jcjo.2016.12.011

9. Parrish RK, Tso MOM. Principles and guidelines of a curriculum for ophthalmic education of medical students: presented by International Task Force on Ophthalmic Education of Medical Students - On behalf of the International Council of Ophthalmology (ICO). Klin Monbl Augenheilkd. 2006;223(SUPPL. 5):S1-19.

10. Dias PLR. An evaluation of the undergraduate teaching programme in ophthalmology in Sri Lanka and Malaysia. Med Educ. 1987;21 (4):334-339. doi:10.1111/j.1365-2923.1987.tb00372.x 
11. Madani FM, Alasiri R, Howldar S, Zagzoog F, Alhibshi N. Perceptions and career expectation in ophthalmology among Saudi undergraduate medical students. Middle East Afr J Ophthalmol. 2018;25(3):142-149. doi:10.4103/meajo.MEAJO 26117

12. Mehmood SI, Kumar A, Al-Binali A, Borleffs JCC. Specialty preferences: trends and perceptions among Saudi undergraduate medical students. Med Teach. 2012;34(SUPPL. 1):S51-S60. doi:10.3109/ 0142159X.2012.656753

13. Succar T, McCluskey P, Grigg J. Enhancing medical student education by implementing a competency-based ophthalmology curriculum. Asia Pac J Ophthalmol. 2017;6(1):59063.

14. Telmesani A, Zaini RG, Ghazi HO. Medical education in Saudi Arabia: a review of recent developments and future challenges. East Mediterr Health J. 2011;17(8):703-707. doi:10.26719/ 2011.17.8.703

15. Noble J, Somal K, Gill HS, Lam WC. An analysis of undergraduate ophthalmology training in Canada. Can J Ophthalmol. 2009;44 (5):513-518. doi:10.3129/i09-127

16. Welch S, Eckstein M. Ophthalmology teaching in medical schools: a survey in the UK. Br $J$ Ophthalmol. 2011;95(5):748-749. doi:10.1136/bjo.2010.195628
17. Shah M, Knoch D, Waxman E. The state of ophthalmology medical student education in the United States and Canada, 2012 through 2013. Ophthalmology. 2014;121(6):1160-1163. doi:10.1016/j. ophtha.2013.12.025

18. Atta IS, Alghamdi A. The efficacy of self-directed learning versus problem-based learning for teaching and learning ophthalmology: a comparative study. Adv Med Educ Pract. 2018;4(9):623-630. doi:10.2147/AMEP.S171328

19. Succar T, Grigg J, Beaver HA, Lee AG. A systematic review of best practices in teaching ophthalmology to medical students. Surv Ophthalmol. 2016;61(1):83-94. doi:10.1016/j.survophthal.20 15.09.001

20. Succar T, Beaver HA, Lee AG. Impact of COVID-19 pandemic on ophthalmology medical student teaching: educational innovations, challenges, and future directions. Surv Ophthalmol. 2021:S00396257(21)00098-9. PMID: 33838164. doi:10.1016/j.survophthal.20 21.03.011
Advances in Medical Education and Practice

\section{Publish your work in this journal}

Advances in Medical Education and Practice is an international, peerreviewed, open access journal that aims to present and publish research on Medical Education covering medical, dental, nursing and allied health care professional education. The journal covers undergraduate education, postgraduate training and continuing medical education

\section{Dovepress}

including emerging trends and innovative models linking education, research, and health care services. The manuscript management system is completely online and includes a very quick and fair peer-review system. Visit http://www.dovepress.com/testimonials.php to read real quotes from published authors. 